\title{
Designing autonomous systems interactions with elderly people
}

\author{
Arsénio Reis ${ }^{1}$, Isabel Barroso ${ }^{2}$, Maria João Monteiroº ${ }^{2}$, Salik Khanal ${ }^{1}$, Vitor Rodri- \\ gues $^{2}$, Vitor Filipe ${ }^{1}$, Hugo Paredes ${ }^{1}$, João Barroso ${ }^{1}$ \\ ${ }^{1}$ INESC TEC and University of Trás-os-Montes e Alto Douro, Vila Real, Portugal \\ \{ars, vfilipe, hparedes, jbarroso\}@utad.pt, \\ salik_khanal@wrc.edu.np \\ ${ }^{2}$ CIDESD and Universidade de Trás-os-Montes e Alto Douro \\ Vila Real, Portugal \\ \{imbarroso, mjmonteiro, vmcpr\}@utad.pt
}

Keywords: Well-being, The Elderly, Ambient Assisted Living, Human Computer Interaction.

\begin{abstract}
Aging is a process inherent to the human condition and part of the human being's life cycle, which can be degraded by the reduction in the individual's physical and social activity. This problem can be augmented by the context in which the person is aging, e.g., family, health and social bonds. The elderly individuals' well-being is related to the strength of their social bonds with their family and friends group, which can be difficult to maintain in some stages of the aging process. A, recently- proposed solution is the adoption of autonomous systems capable of autonomous interactions with the elderly. Such systems are designed to be able to interpret the individual's state of mind and the current context in order to conduct an effective interaction with the elderly person. This study focuses on the interaction design between the autonomous system and the human person, by considering the elderly individual's context and pursuing the type of interaction that will positively influence the reinforcement or maintenance of the person's social bonds with the family and friends groups. The study was carried out by interviewing a group of elderly people, currently living in nursing homes and with limited access to their family and friends.
\end{abstract}

\section{Introduction}

The aging process is part of the life cycle of every living creature and is inherent to the human condition. Aging can degrade the human life by introducing considerable reductions in the individual's physical and social activities, which may lead to a reduction of the individuals' social bonds with the Family, Friends and former Co-Workers

adfa, p. 1, 2011.

(C) Springer-Verlag Berlin Heidelberg 2011 
(FFxCW) group [1][2]. This problem can be further augmented by the specific context of the aging person, e.g., family, health and social bonds [3][4]. In some stages of the aging process it is difficult to maintain the strength of social bonds, and considering that the individuals' well-being is related to the strength of these social bonds, then acting in order to maintain the individual's social activities is an important issue to address [5][6].

Recently, the use of digital assistants has been proposed to engage and assist the elderly to develop social activities with their FFxWC group [7][8]. These assistants, proposed as autonomous systems, would be capable of interpreting the individual's state of mind and the current context, as well as to conduct an effective interaction with the elderly person [9]. A component of this model is the catalogue of interactions that would be available to the autonomous systems [10].

In this study we have focused on the current status and motivation of the elderly regarding what they miss the most and how they would accept the interaction with a digital assistant. The objective is to understand the factors that would influence the successful design of human-computer interactions, in particular those types of interaction that will positively influence the reinforcement or maintenance of the person's social bonds with the FFxCW group [11]. A group of elderly individuals, currently living in nursing homes and with limited access to their family and friends, was individually interviewed.

\section{The survey}

This study was conducted as a survey, focused on elderly people living in care centres, which might have caused them to experience some form of social deprivation.

\subsection{Objectives}

The survey was designed in order to comply with the following specific objectives:

1. To characterize the individual population permanently residing in care centres.

2. To determine the current social circumstances of the population regarding their relationship with family, friends and former co-workers.

3. To identify what the individuals miss regarding their relationships with their social peers.

4. To assess the individuals' motivation to accept and use ICT- based systems and applications.

\subsection{The population}

The survey was conducted using a set of twenty people, each one individually interviewed. 


\subsection{The questions}

The survey was designed with twenty five questions, some of which were composed of several sub-questions. The overall questions were arranged in four groups:

1. Characterization;

2. Current situation;

3. Life aspects missed the most;

4. Motivation to use electronic assistants.

\section{Survey analysis}

In this section we analyse the survey according to the four groups of questions.

\subsection{Characterization}

This feature characterises the interviewed population regarding the following categories: Gender, Marital status, Educational level, Mobile phone usage, and Computer usage. They are mostly over 70 years old (50\%); more women $(65 \%)$; and have or had marital relationships $(80 \%)$.

Regarding the educational level, $20 \%$ can't read or write and the other $80 \%$ has various levels of education. More than $50 \%$ uses a mobile phone daily (53\%), but only $5 \%$ uses a computer, and only occasionally.

\subsection{Current situation}

In this category we analysed the current situation of the individuals, namely: Reason for living in a care centre, Interaction with visitors, Relationship with the family, Relationship with the other residents in the centre, Relationship with the staff, Current health disabilities, and Daily activities.

For all the individuals interviewed, the reason for currently living in the care centre is directly related to some form of loneliness, distributed as follows:

- The family lives in a distant geographical location (10\%);

- The family did not have time to take care of them (15\%);

- Worsening of health condition (15\%);

- Physical dependence (10\%);

- Difficulty performing daily tasks $(5 \%)$;

- Death of spouse $(5 \%)$;

- Loss of autonomy (10\%);

- Fear of loneliness (10\%);

- I lived alone (20\%).

Most individuals (95\%) have some regular visits, mostly from family members $(75 \%)$ or some other friends $(20 \%)$. This visits are mainly weekly (60\%). 
Regarding their current relationships, more that $60 \%$ consider to have a good or very good relationship with the others (family, friends centre staff, etc.).

The majority of the individuals have some sort of health problem $(95 \%)$, distributed as follows:

- Endocrine gland disease, metabolism and immune disorders $(31,6 \%)$;

- Circulatory System Disease (10,5);

- Respiratory system disease $(10,5)$;

- Disease of the nervous system and sense organs ((10,5);

- Osteomuscular and Connective Tissue System Disease $(15,8)$;

- Neoplasm (10\%);

- Mental disorder (10\%).

These health issues also manifest as disabilities (75\%), mostly causing mobility problems (53\%) and sight problems (40\%).

Despite the health issues, all individuals classified themselves as active, carrying out the following activities throughout the day:

- Doing activities related to crafts $(5,3 \%)$;

- Gardening (5,3\%);

- Knitting (such as sweaters) $(10,5 \%)$;

- Outdoor tours $(15,8 \%)$;

- Playing games (cards, checkers) $(5,3 \%)$;

- Reading (newspapers or books) $(5,3 \%)$;

- Watching TV $(52,6 \%)$.

\subsection{The latest changes in life and what aspects are missed the most}

In this group we analysed the life aspects that the individual might miss the most in their current life:

Changes in the social relations with Family, Friends and former Co-Workers (FMxCW);

- Activities missed the most;

- Internet usage by FFxCW;

- Updates from FFxCW;

- Increase in contacts with FFxCW;

- Reasons why they do not have more FFxCW interaction.

A slight majority of the individuals (55\%) agrees that their contacts with the FFxWC groups have decreased in the last years, while the others (40\%) think they have the same level of contact now as before. The frequency of those contacts is mostly daily $(50 \%)$ and decreases for more extended periods.

When asked about having more frequent contacts with people from the FFxCW groups, a vast majority was in favor (85\%), while a minority $(15 \%)$ wasn't interested. There wasn't a considerable preference about any of the FFxCW groups. 
The main reasons for not getting in touch more often with FFxCWs were:

1. Lack of resources;

2. Lack of reasons or subjects;

3. Other reasons.

When asked about what they miss the most and would like to be currently engaged in, the following list was compiled:

1. Contacting family;

2. Learning to use a computer;

3. Making trips and sightseeing;

4. Growing a vegetable garden;

5. Reading books;

6. Contacting friends;

7. Playing social games;

8. Contacting old co-workers;

9. Working;

10. Listening to music;

11. Playing sports;

12. Hunting or fishing.

To the interviewed individual's knowledge, all of the people from their current FFxCW groups are using some sort of internet service, mostly on a daily basis (85\%).

\subsection{Motivation to use electronic assistants}

In this group we analysed several aspects regarding the acceptance and motivation for the elderly to use a digital personal assistant and some possible types of interaction.

The survey included the following interactions:

1. Interaction with an electronic assistant;

2. Assistance in daily life activities;

3. Email management;

4. Information about activities in social media;

5. Leisure activities (social gaming).

After being explained the concept of a digital personal assistant, a vast majority $(85 \%)$ considered it "interesting or "very interesting". Half of the individuals $(50 \%)$ expressed an interest in trying to use a device with a digital assistant.

The following figuresErro! A origem da referência não foi encontrada. describe the motivation for engaging in specific activities with the collaboration of the digital assistant. The numbers, expressed as percentages, clearly show that there is a strong motivation regarding the usage of a digital assistant in all the proposed activities. The column "Positive" reports the cumulative positive answers and is classified as $85 \%$ or $95 \%$. We interpret this as strong motivation. 
In Fig. 1., regarding the adoption of an electronic assistant, there is a strong and positive answer, with half the individuals expressing their will to try and experiment an electronic assistant.

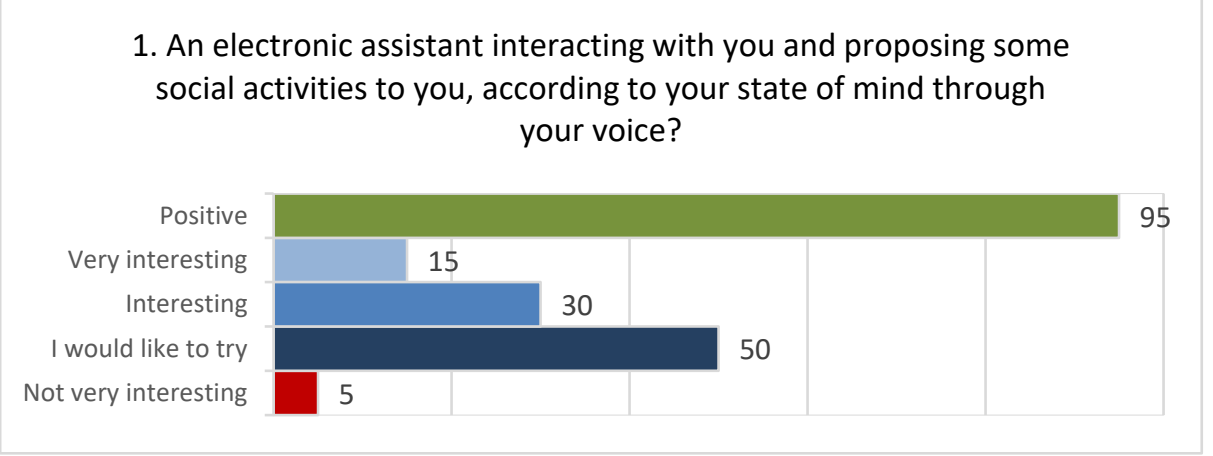

Fig. 1. - Interaction with an electronic assistant.

In Fig. 2., there is a strong positive reaction regarding the assistance in the daily life activities, but the majority of the individuals doesn't explicitly expresses their will to try.

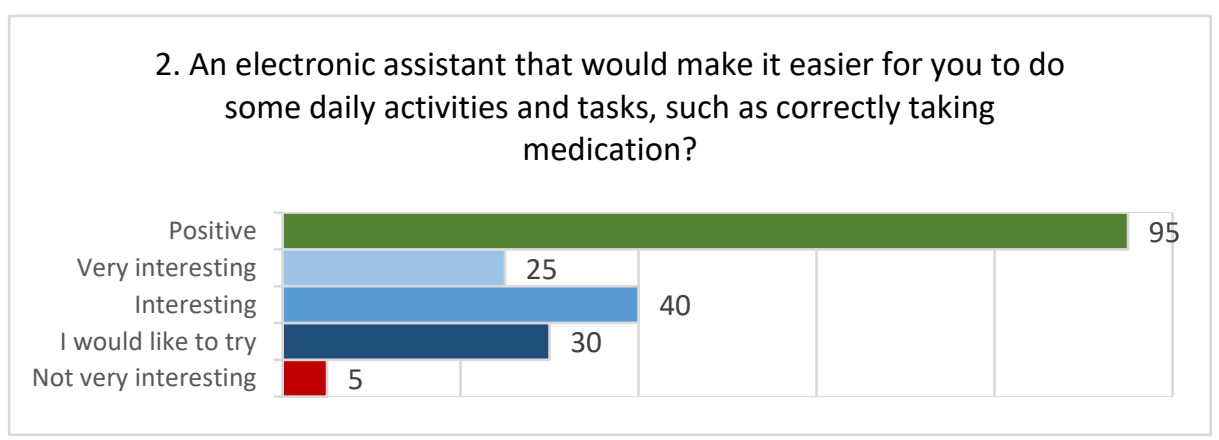

Fig. 2. - Assistance in daily life activities.

In Fig. 3., there is a clear interest in trying an assistive system for mail management, which might be due to the lack of knowledge, by this elderly population, on how to use a mail system 


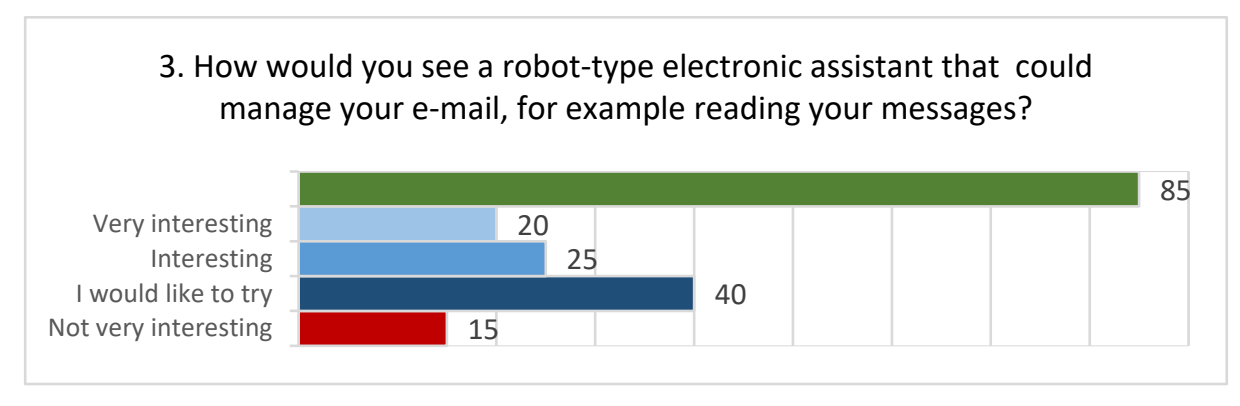

Fig. 3. Email management

As in Fig. 3., the answers in Fig. 4, are similar, which might be justified by the fact that the interviewed individuals' don't have the necessary expertise to properly use some common electronic services (e.g., mail, social media, etc.) and would be happy to try with the help of an electronic assistant.

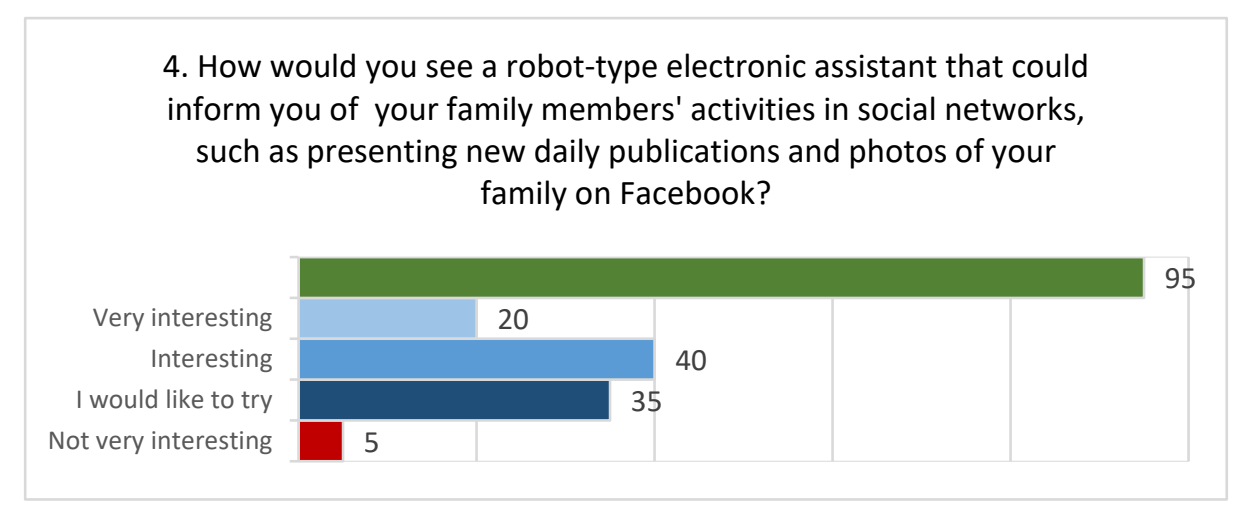

Fig. 4. - Social media management.

Social games usage, represented in Fig. 5., are a well-known activity, for which the individuals have a clear interest, but don't really have a strong will to try with an electronic assistant. A reason, for this discrepancy between "interesting" and "like to try", might be justified by the fact that, currently, they can use social games whenever they like, and so, don't necessarily depend of the introduction of an assistant. 


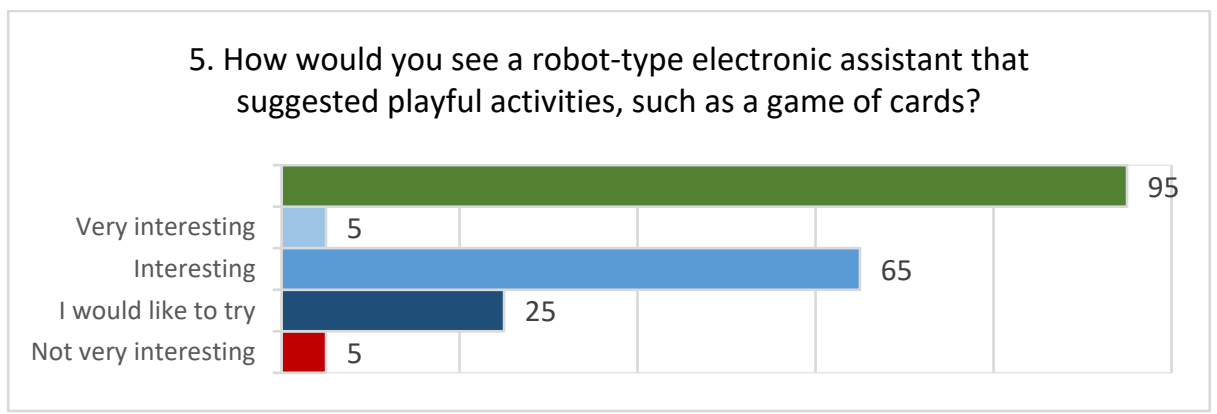

Fig. 5. - Social games

\section{Conclusions}

The elderly people in a care centre are mostly old people (over 70 years old), with some sort of chronic health problem, who moved to the care centre due to a loneliness-related problem. They have good social relations with other people, but these tend to be limited by living in the centre and frequently also by mobility and sight problems, which has caused their relationship circle to decrease. Most of these elderly people receive weekly visits from their families and would be happy to have more contact with other people outside the care centre. They also consider themselves active persons, but half of them include "watching TV" as a daily activity. The major reason for not have a wider range of activities and relation is related to their lack of resources.

After analysing this survey, we concluded that the necessary conditions exist for introducing the digital assistant with the main objective of mitigating the problems of social segregation associated with: the residence in the care centre; the lack of mobility and sight; and the lack of resources to engage in activities.

There is a strong motivation for the elderly to adopt the digital assistant option, we think mostly due to the lack of other solutions for the problems of increasing social isolation. However, there is an obstacle related to adopting the technology, which is well expressed by the numbers of about $50 \%$ of phone users and only $5 \%$ of computer users. Nevertheless, the model of interaction proposed is based on natural language and adaptive interfaces, which, should conceal the underlying technology in excellent conditions.

A last conclusion, regarding the motivation to use electronic assistants, can be drawn from the answer pattern in 3.4 , in which they express a strong will to try an electronic assistant in scenarios where they don't have the expertise to use electronic systems by themselves. In this cases, e.g., mail management, social media management, the individuals are willing to immediately try an electronic assistant. It is an interesting conclusion, in the sense that shows the individuals' open mind to new technology and devices, although their advance age and isolation. 


\section{$5 \quad$ Future work}

The future work will follow-up to test and evaluate specific interactions with the elderly. During the first phase, a set of interactions will be fully developed, by specifying specific interaction scripts and creating digital mock-ups; in a second phase, those mock-ups will be used with the elderly and an assessment will be produced. Another cycle to develop/assess may be necessary in order to proceed to a prototype production scenario.

Acknowledgements. This work was supported by Project "NanoSTIMA: Macro-toNano Human Sensing: Towards Integrated Multimodal Health Monitoring and Analytics/NORTE-01-0145-FEDER-000016" financed by the North Portugal Regional Operational Programme (NORTE 2020), under the PORTUGAL 2020 Partnership Agreement, and through the European Regional Development Fund (ERDF).

\section{References}

[1] Instituto Nacional de Estatística (2011). Censos 2011-Resultados Provisórios. http://censos.ine.pt/xpor-

$\mathrm{tal} / \mathrm{xmain}$ ?xpid=CENSOS\&xpgid=ine_censos_publicacao_det\&contexto=pu\&PUBLI CACOESpub_boui $=122073978 \&$ PUBLICACOESmodo $=2 \&$ selTab=tab1\&pcensos $=61969554$

[2] Instituto Nacional de Estatística (2012). O Envelhecimento em Portugal. Situação demográfica e socio-económica recente das pessoas idosas, Serviço de Estudos sobre a População do Departamento de Estatísticas Censitárias e da População.

[3] Fernandes, A. (2001). Velhice, solidariedades familiares e política social: itinerário de pesquisa em torno do aumento da esperança de vida. Sociologia, Problemas e Práticas [online], n.36, pp.39-52.

[4] Reis, A., Lains, J., Paredes, H., Filipe, V., Abrantes, C., Ferreira, F., ... \& Barroso, J. (2016, July). Developing a System for Post-Stroke Rehabilitation: An Exergames Ap-proach. In International Conference on Universal Access in Human-Computer Interaction (pp. 403-413). Springer International Publishing.

[5] Conselho Económico e Social (2013). Parecer de iniciativa sobre as consequências económicas, sociais e organizacionais decorrentes do envelhecimento da população. Lisboa:

[6] Reis, A., Barroso, J., \& Gonçalves, R. (2013, July). Supporting accessibility in higher education information systems. In International Conference on Universal Access in Human-Computer Interaction (pp. 250-255). Springer Berlin Heidelberg.

[7] Sun, H., De Florio, V., Gui, N., \& Blondia, C. (2009, April). Promises and challenges of ambient assisted living systems. In Information Technology: New Generations, 2009. ITNG'09. Sixth International Conference on (pp. 1201-1207). Ieee.

[8] Steg, H., \& Strese, H. (2005). Ambient assisted living-european overview report. 
[9] Arsénio Reis, Hugo Paredes, Isabel Barroso, Maria João Monteiro, Vitor Rodrigues, Salik Khanal, João Barroso (2016). Autonomous systems to support social activity of elderly people - A prospective approach to a system design. TISHW2016. International Conference on Technology and Innovation on Sports, Health and wellbeing. December 1-3, 2016 - UTAD, Vila Real, Portugal.

[10] Reza K., Sima S., \& Mei-Tai Chu (2014). Socially Assistive Robots in Elderly Care: A Mixed-Method Systematic Literature Review. Intl. Journal of Human-Computer Interaction, 30: 369-393.

[11] Reis, A., Reis, C., Morgado, L., Borges, J., Tavares, F., Gonýalves, R., ... \& Cruz, J. B. (2016, June). Management of surgery waiting lists in the Portuguese public healthcare network: The information system for waiting list recovery programs. In Information Systems and Technologies (CISTI), 2016 11th Iberian Conference on (pp. 17). AISTI. 